\title{
Uso de cáscara de huevo molida como material encalante en un suelo ácido del Perú
}

\author{
Use of milled eggshell as a liming material in an acidic soil of Peru \\ Antoni Huanca, Sady García ${ }^{1 *}$
}

\begin{abstract}
RESUMEN
El crecimiento de la industria avícola en el Perú ha incrementado la producción de cáscaras de huevo. Este material tiene interés por su potencial como enmienda química en suelos ácidos. La presente investigación fue realizada en laboratorio con el objetivo de determinar la factibilidad del uso de la cáscara de huevo molida como enmienda encalante y fuente de calcio biodisponible. Un suelo ácido de Ucayali fue enmendado con cáscara de huevo molida de dos tamaños de partícula: fracción fina (53-106 $\mu \mathrm{m})$ y sin $\operatorname{tamizar}(<1,7 \mathrm{~mm})$. Las fracciones fueron aplicadas en dosis equivalentes a 100, 200 y 400\% de la acidez cambiable incluyendo un tratamiento sin enmienda como control. El suelo fue incubado a temperatura ambiente durante 135 días. El pH, la acidez cambiable y los contenidos de calcio cambiable $(\mathrm{KCl} 1 \mathrm{~N})$ y extractable (Mehlich-3) en el suelo fueron determinados a los 45, 90 y 135 días de incubación. Ambas fracciones mostraron un comportamiento similar en las variables evaluadas. El pH y los contenidos de calcio cambiable y extractable del suelo se incrementaron en forma proporcional a la dosis empleada. La dosis equivalente a $100 \%$ de la acidez cambiable permitió alcanzar valores de $\mathrm{pH}$ inferiores a 5,4, pero fue suficiente para neutralizar toda la acidez cambiable a partir de 45 días. El calcio extractable mostró alta correlación con el calcio cambiable. La cáscara de huevo molida presentó un alto potencial como enmienda encalante para suelos ácidos de la Amazonía.

Palabras clave: Cáscara de huevo, acidez del suelo, encalado, calcio extractable.
\end{abstract}

\begin{abstract}
The growth of poultry industry in Peru has increased the production of eggshell. This material is interesting as a chemical amendment for acidic soils. The present research was conducted under laboratory conditions with the aim of studying the feasibility of using milled eggshells as liming material and source of bioavailable calcium. An acid soil of Ucayali was amended with milled eggshell in two particle sizes: fine powder $(53-106 \mu \mathrm{m})$ and non-sieved $(<1.7 \mathrm{~mm})$. Both fractions were applied at rates equivalent to 100 , 200 an $400 \%$ of exchangeable acidity including one control without amendment. The soil was incubated at room temperature during 135 days. Soil pH, exchangeable acidity and contents of exchangeable (KCl $1 \mathrm{~N})$ and extractable calcium (Mehlich-3) were measured at 45, 90 and 135 days of incubation. Both fractions showed very similar effect on evaluated variables. Soil pH and contents of exchangeable, and extractable calcium increased proportionally to the rate applied. The rate equivalent to $100 \%$ of exchangeable acidity allowed to reach $\mathrm{pH}$ values lower than 5.4 but it was enough to neutralize all the exchangeable acidity since 45 days. Extractable calcium showed a high correlation with exchangeable calcium. Milled eggshell showed a high potential as a liming material for acidic soils of the Amazonia.
\end{abstract}

Key word: Eggshell, soil acidity, liming, extractable calcium.

\section{Introducción}

El Perú se ubica entre los 20 principales productores avícolas del mundo. Durante la última década, la producción y el consumo de aves se duplicaron, alcanzando a 1.56 millones de toneladas en el 2017. El estimado de producción mensual para el 2018 fue de 61 millones de unidades mensuales (Diario Gestión, 2018). Este incremento resulta también en una mayor generación de residuos sólidos, incluyendo la cáscara de huevo, que puede acumularse en incubadoras y centros de producción de aves para engorde.

La cáscara de huevo es una bio-cerámica porosa (Panheleux et al., 1999; Hincke et al., 2012) formada por varias capas mineralizadas y orgánicas. Las capas externas pueden contener hasta $95 \%$ de carbonato de calcio en peso (Romanoff y Romanoff, 1949; Parsons, 1982), además de pequeñas cantidades de magnesio,

\footnotetext{
1 Departamento Académico de Suelos, Universidad Nacional Agraria La Molina, Lima-Perú.

* Autor de correspondencia: sjgarciab@lamolina.edu.pe Av. La Molina s/n, La Molina, Lima-Perú.
} 
fósforo y elementos menores (Nys et al., 1999), mientras que las membranas internas son ricas en proteínas (Nys et al., 2004). El contenido de $\mathrm{CaCO}_{3}$ en la cáscara de huevo le confiere interés como enmienda encalante para los suelos ácidos (King'ori, 2011). Diversos autores han mostrado el efecto de la aplicación de cáscaras de huevo molidas en la corrección de la acidez del suelo, la provisión de calcio y el incremento del rendimiento de los cultivos (Holmes y Kassel, 2006; Holmes y Rueber, 2013).

La eficacia de un material encalante depende de su pureza y del grado de finura del material (Barber, 1984). Los materiales de molienda más fina tienen una mayor superficie específica y resultan en mayor velocidad de reacción (Haby y Leonard, 2002), si bien se puede presentar el efecto de sellado de poros. Este trabajo de investigación busca evaluar el efecto de la aplicación de cáscara de huevo molida, tanto tamizada finamente como sin tamizar, sobre el $\mathrm{pH}$, la acidez cambiable y los contenidos de calcio cambiable y extractable en un suelo ácido de la Amazonía peruana, a nivel de laboratorio.

\section{Materiales y Métodos}

\section{Obtención y preparación de materiales}

La cáscara de huevo fue obtenida de la planta de incubación de pollos de la empresa San Fernando S.A. (distrito de Chancay, región Lima). La cáscara se limpió separando los residuos superficiales y fue molida empleando un molino eléctrico sin remover las membranas. Luego de la molienda, el material fue tamizado secuencialmente a través de tamices con mallas de 60, 140 y 270 mesh (aberturas de 250, 105 y $53 \mu \mathrm{m}$, respectivamente). Los porcentajes de material que pasaron cada malla fueron $94,8 \%$, $77,4 \%$ y $4,5 \%$, respectivamente. La cáscara molida sin tamizar y la fracción de molienda contenida entre las mallas de 53 y $105 \mu \mathrm{m}$ (de aquí en adelante fracción fina) fueron seleccionadas como materiales encalantes experimentales. Esta última fracción fue elegida por ser la que se obtuvo en mayor cantidad (72,9\%) en la molienda. El contenido de nitrógeno en ambas fracciones fue determinado por el método de micro-kjeldahl (Yuen y Pollard, 1953). El contenido de $\mathrm{CaCO}_{3}$ se determinó por reacción con $\mathrm{HCl}$ y posterior retrovaloración. Los contenidos de $\mathrm{N}$ y de $\mathrm{CaCO}_{3}$ fueron de 2,1\% y $73 \%$ en la cáscara molida sin tamizar, y de $1,8 \%$ y $70 \%$ en la fracción fina, respectivamente. Las eficiencias de finura, calculadas a partir del tamaño promedio de partícula (Barber, 1984), fueron de $95 \%$ y $100 \%$ para la cáscara sin tamizar y la fracción fina, respectivamente.

El suelo experimental fue obtenido de la capa arable $(20 \mathrm{~cm})$ de un campo agrícola ubicado en el distrito de Yarinacocha (región Ucayali). Luego del muestreo, el suelo fue secado al aire, desterronado y tamizado en malla de 10 mesh ( $2 \mathrm{~mm}$ de abertura) para ser sometido a análisis. Las características del suelo fueron las siguientes: arena, 41\%; limo, 36\%; arcilla, 23\%; $\mathrm{pH}\left(\mathrm{H}_{2} \mathrm{O}\right)$, 4,98; C orgánico total, $3,2 \mathrm{~g} \mathrm{~kg}^{-1}$; $\mathrm{P}$ extractable (Olsen), 3,5 mg kg-1; $\mathrm{K}$ extractable (acetato de amonio), $27 \mathrm{mg} \mathrm{kg}^{-1}$; CIC total, 9,28 cmolc kg-1;

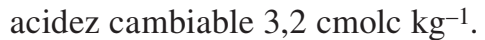

\section{Incubación de las enmiendas}

La prueba de incubación fue realizada en el laboratorio de análisis de suelos, plantas, aguas y fertilizantes de la Universidad Nacional Agraria La Molina (LASPAF-UNALM). Porciones de $200 \mathrm{~g}$ de suelo fueron colocadas en frascos de plástico con tapa hermética. Los materiales encalantes se aplicaron en cantidad suficiente para neutralizar 3,2, 6,4 y $12,8 \mathrm{cmolc} \mathrm{kg}^{-1}$ de acidez $(100 \%, 200 \%$ y $400 \%$ de la acidez cambiable del suelo). Las porciones de cáscara sin tamizar necesarias para estas dosis fueron de $0,45 \mathrm{~g}, 0,90 \mathrm{~g}$ y $1,80 \mathrm{~g}$, respectivamente, en tanto que para la fracción fina fueron de $0,43 \mathrm{~g}$, 0,86 g y 1,72 g. Un tratamiento sin aplicación de enmienda fue incluido como testigo. Se instalaron doce frascos por cada tratamiento. El suelo fue mezclado uniformemente con las enmiendas y humedecido a $50 \%$ de la máxima capacidad de retención con agua destilada. Luego los frascos fueron cerrados herméticamente e incubados en un ambiente oscuro con temperatura entre 22 y $25^{\circ} \mathrm{C}$. Durante la incubación se agregó agua destilada cada semana para mantener la humedad del suelo (Ok et al., 2011).

\section{Análisis químico}

Las mezclas de suelo y enmienda fueron incubadas durante 135 días y evaluadas en tres momentos (45, 90 días y 135 días de incubación). Cuatro frascos fueron seleccionados en cada 
evaluación en un muestreo sin reemplazo. El pH se determinó empleando una relación suelo-agua de 1:1; la acidez cambiable fue determinada por el método descrito por Yuan (1959); el calcio cambiable fue determinado por desplazamiento con $\mathrm{KCl} 1 \mathrm{~N}$ y posterior espectrofotometría de absorción atómica (Miyazawa et al., 2001). Se utilizó $\mathrm{KCl}$ en vez de $\mathrm{CH}_{3} \mathrm{COONH}_{4}($ Ciesielski et al., 1997) para evitar la disolución del calcio de las cáscaras sin reaccionar. El calcio extractable fue determinado empleando la solución extractante Mehlich-3 (Mehlich, 1984).

\section{Análisis estadístico}

Los datos obtenidos en los diferentes tratamientos fueron sometidos sin transformación al análisis de variancia (ANVA). Los promedios de los tratamientos fueron comparados mediante la prueba de comparación de medias HSD de Tukey. Para el análisis estadístico se empleó el paquete Agricolae del ambiente para cómputo estadístico R, versión 3.4.3 (R Core Team, 2017).

\section{Resultados y Discusión}

\section{Variación del pH en el suelo}

El tiempo de incubación no afectó el pH del suelo sin enmienda encalante. La aplicación de cáscara de huevo molida resultó en un incremento significativo del $\mathrm{pH}$ del suelo experimental. Este incremento se pudo apreciar desde los 45 días de incubación y se relacionó directamente con la dosis aplicada (Tabla 1). En todas las dosis aplicadas el pH se incrementó ligeramente hasta los 90 días de incubación para posteriormente estabilizarse a los 135 días en valores promedio de 5,10, 6,81 y 7,54, para las dosis equivalentes a $100 \%, 200 \%$ y $400 \%$ de la acidez cambiable, respectivamente. En general, la dosis de $200 \%$ fue suficiente para alcanzar valores de $\mathrm{pH}$ cercanos a la neutralidad.

El tamaño de partícula no influyó significativamente en el efecto de la cáscara de huevo molida sobre el pH del suelo (Tabla 1). Las fracciones fina y sin tamizar arrojaron valores estadísticamente similares en el $\mathrm{pH}$ del suelo en todas las dosis aplicadas. Solo a la dosis de $200 \%$ de la acidez cambiable y a los 135 días de incubación, el pH del suelo enmendado con la fracción sin tamizar superó a aquel enmendado con la fracción fina.
Tabla 1. Efecto de la aplicación de cáscara de huevo molida (fracciones fina y sin tamizar) sobre el $\mathrm{pH}$ de un suelo ácido durante un periodo de incubación de 135 días.

\begin{tabular}{clccc}
\hline \multirow{2}{*}{$\begin{array}{c}\text { Dosis } \\
(\% \text { de AC) }\end{array}$} & Fracción & \multicolumn{3}{c}{ Tiempo de incubación (días) } \\
\cline { 3 - 5 } & & 45 & 90 & 135 \\
\hline \multirow{2}{*}{100} & Fina & $4,07 \mathrm{a}$ & $4,19 \mathrm{a}$ & $4,02 \mathrm{a}$ \\
& Sin tamizar & $5,04 \mathrm{~b}$ & $5,30 \mathrm{~b}$ & $5,02 \mathrm{~b}$ \\
\multirow{2}{*}{200} & Fina & $6,56 \mathrm{c}$ & $5,34 \mathrm{~b}$ & $5,18 \mathrm{~b}$ \\
& Sin tamizar & $6,80 \mathrm{c}$ & $6,92 \mathrm{c}$ & $6,66 \mathrm{c}$ \\
\multirow{2}{*}{400} & Fina & $7,11 \mathrm{~d}$ & $7,56 \mathrm{~d}$ & $7,45 \mathrm{~d}$ \\
& Sin tamizar & $7,14 \mathrm{~d}$ & $7,57 \mathrm{~d}$ & $7,63 \mathrm{e}$ \\
\hline \multirow{2}{*}{ Dosis } & & $* * *$ & $* * *$ & $* * *$ \\
Fracción & & n.s. & n.s. & $* * *$ \\
Int. dosis x fracción & n.s. & n.s. & $*$ \\
\hline
\end{tabular}

Los valores dentro de cada columna seguidos por la misma letra no son significativamente diferentes a $\mathrm{P}<0,05$, de acuerdo a la prueba de comparación de medias HSD de Tukey. Niveles de significación: 'n.s.' $>0.05$, '*' $<0.05$, '**' $<0.01$, '***' $<0.001$.

\section{Acidez cambiable}

La incubación disminuyó ligera y gradualmente la acidez cambiable del suelo. Este efecto puede deberse al equilibrio alcanzado entre los cationes intercambiables con aquellos presentes en la solución suelo (Curtin y Smillie, 1995) luego de humedecer el suelo. La aplicación de cáscara molida sin tamizar disminuyó significativamente la acidez cambiable, alcanzándose la neutralización casi total en todas las dosis de encalado desde los 45 días de incubación (Figura 1) y hasta el final

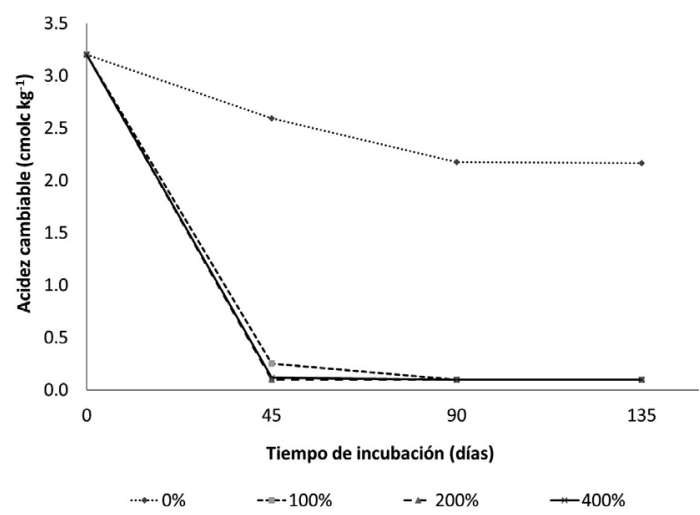

Figura 1. Efectos de la aplicación de cáscara de huevo molida sin tamizar (dosis equivalentes a 0,100, 200 y $400 \%$ de la acidez cambiable) sobre la acidez cambiable de un suelo ácido durante un periodo de incubación de 135 días. 
del experimento. La disminución de la acidez cambiable no fue afectada por el tamaño de partícula (Tabla 2). Estos resultados parecen señalar que si bien la dosis de encalado equivalente a $100 \%$ de la acidez cambiable no permite alcanzar un $\mathrm{pH}$ superior a 5,4, considerado como indicador de la neutralización del aluminio (Kamprath, 1970), sí es suficiente para neutralizar la acidez cambiable que puede resultar tóxica para las plantas.

\section{Calcio cambiable y extractable}

La aplicación de cáscara de huevo sin tamizar incrementó significativamente el contenido de calcio cambiable (en $\mathrm{KCl}$ ) del suelo. Este efecto fue notorio desde los 45 días de incubación y se relacionó directamente con la dosis aplicada. El calcio cambiable se incrementó a los 90 días y disminuyó a los 135 días (Figura 2). No se apreciaron diferencias significativas entre los dos tamaños de partícula para el contenido de calcio cambiable (Tabla 2).

El contenido de calcio extractable (Mehlich-3) mostró un comportamiento similar al del calcio cambiable. Todas las dosis empleadas aumentaron significativamente el calcio extractable con respecto al suelo sin enmienda. El incremento fue proporcional a la dosis aplicada. Hasta los 90 días de incubación, el calcio extractable del suelo enmendado con cáscara de huevo sin tamizar

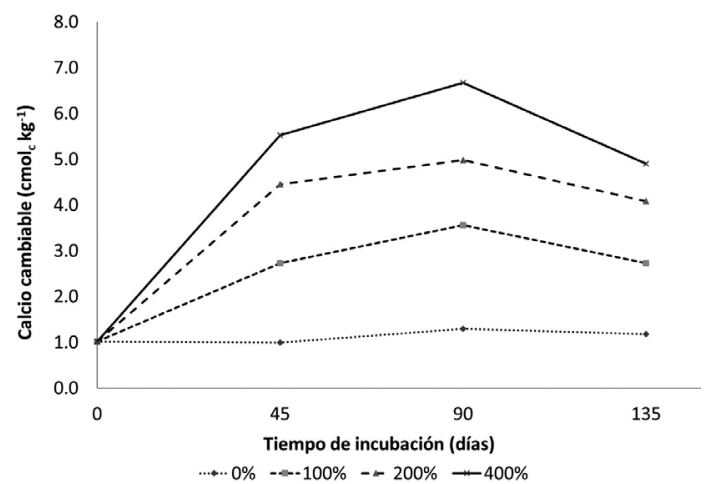

Figura 2. Efectos de la aplicación de cáscara de huevo molida sin tamizar (dosis equivalentes a 0,100, 200 y $400 \%$ de la acidez cambiable) sobre el contenido de calcio cambiable $(\mathrm{KCl} 1 \mathrm{~N})$ de un suelo ácido durante un periodo de incubación de 135 días.

aumentó gradualmente, mientras que, a los 135 días de incubación, disminuyó marcadamente en la dosis equivalente a $400 \%$ de la acidez cambiable y se mantuvo constante en las otras dosis (Figura 3). La liberación del calcio contenido en la cáscara de huevo molida puede ser acelerada por la reacción fuertemente ácida del suelo y por la actividad bacteriana que toma parte activa en la descomposición de la cáscara de huevo (Smith y Hayward, 2010). La disminución de calcio cambiable que se observó posiblemente se debió al proceso de carbonatación ocasionado por el elevado $\mathrm{pH}$ y la baja concentración de $\mathrm{CO}_{2}$ en el suelo. Los contenidos de calcio cambiable y calcio extractable

Tabla 2. Efecto de la aplicación de cáscara de huevo molida (fracciones fina y sin tamizar) sobre la acidez cambiable y los contenidos de calcio cambiable y extractable de un suelo ácido (135 días de incubación).

\begin{tabular}{|c|c|c|c|c|}
\hline \multirow{2}{*}{ Dosis (\% de AC) } & \multirow{2}{*}{ Fracción } & Acidez cambiable & Calcio cambiable & Calcio extractable \\
\hline & & \multicolumn{3}{|c|}{$\left(\mathrm{cmol}_{\mathrm{c}} \mathrm{kg}^{-1}\right)$} \\
\hline 0 & & $2,17 \mathrm{a}$ & $1,19 \mathrm{a}$ & $1,95 \mathrm{a}$ \\
\hline \multirow{2}{*}{100} & Fina & $0,10 \mathrm{~b}$ & $3,00 \mathrm{~b}$ & $3,43 b$ \\
\hline & Sin tamizar & $0,10 \mathrm{~b}$ & $2,73 b$ & $3,70 \mathrm{~b}$ \\
\hline \multirow[t]{2}{*}{200} & Fina & $0,10 \mathrm{~b}$ & $4,18 \mathrm{c}$ & $5,05 \mathrm{c}$ \\
\hline & Sin tamizar & $0,10 \mathrm{~b}$ & $4,08 \mathrm{c}$ & $5,06 \mathrm{c}$ \\
\hline \multirow[t]{2}{*}{400} & Fina & $0,10 \mathrm{~b}$ & $4,93 d$ & $5,56 \mathrm{~d}$ \\
\hline & Sin tamizar & $0,10 \mathrm{~b}$ & $4,90 \mathrm{~d}$ & $5,33 \mathrm{dc}$ \\
\hline Dosis & & $* * *$ & $* * *$ & $* * *$ \\
\hline Fracción & & n.s. & n.s & n.s \\
\hline Int. dosis $\mathrm{x}$ fracció & & n.s & n.s & $*$ \\
\hline
\end{tabular}

Los valores dentro de cada columna seguidos por la misma letra no son significativamente diferentes a P $<0,05$, de acuerdo a la prueba de comparación de medias HSD de Tukey. Niveles de significación: 'n.s.' $>0.05$, '*' $<0.05$, '**' $<0.01$, '***' $<0.001$. 


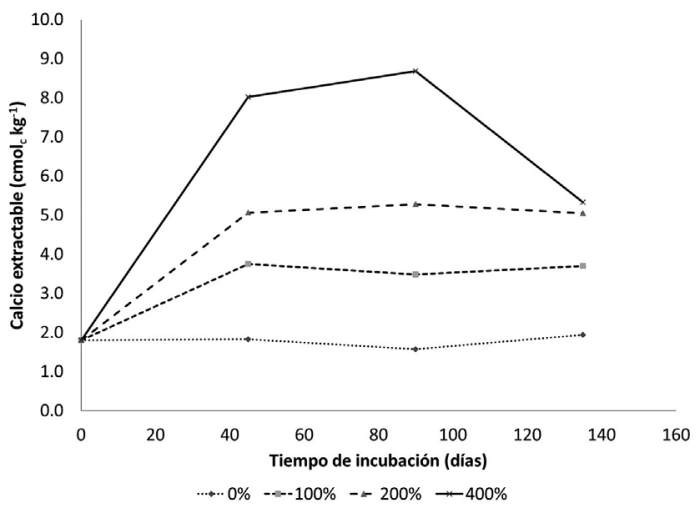

Figura 3. Efectos de la aplicación de cáscara de huevo molida sin tamizar (dosis equivalentes a 0, 100, 200 y $400 \%$ de la acidez cambiable) sobre el contenido de calcio extractable (Mehlich-3) de un suelo ácido durante un periodo de incubación de 135 días.

mostraron estrecha correlación, especialmente a los 135 días de incubación (Figura 4), lo cual indica que la extracción de calcio con la solución de Mehlich-3 es un buen estimador de la disponibilidad de calcio en un suelo ácido.

\section{Conclusiones}

La aplicación de cáscara de huevo molida mostró efectos muy favorables en la corrección del suelo ácido experimental: incremento del $\mathrm{pH}$, neutralización de la acidez cambiable e incremento de las fracciones biodisponibles de calcio. Las fracciones de cáscara de huevo molida fina y sin tamizar presentaron efectos similares sobre todas las variables evaluadas, lo que parece indicar que la cáscara molida no requiere de un tamizado posterior mientras aproximadamente $75 \%$ del material pueda

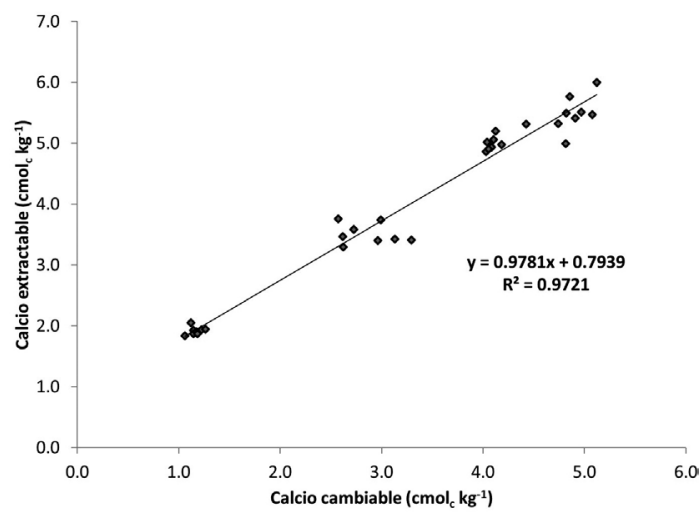

Figura 4. Correlación entre los contenidos de calcio extractable (Mehlich-3) y calcio cambiable ( $\mathrm{KCl} 1 \mathrm{~N})$ de un suelo ácido enmendado con cáscara de huevo molida a los 135 días de incubación.

pasar una malla de partículas menores de 140 mesh. El calcio extractable (con solución de Mehlich-3) se correlacionó estrechamente con el calcio cambiable en el suelo. En general, la cáscara de huevo molida es un material encalante muy promisorio para la corrección de suelos ácidos, requiriendo pruebas de campo para la recomendación de dosis adecuadas.

\section{Agradecimientos}

Agradecemos al Programa Nacional de Innovación para la Competitividad y Productividad (Innóvate Perú) y a la Empresa Avícola San Fernando por el soporte financiero de la presente investigación mediante el proyecto Desarrollo de fertilizantes peletizados y/o granulados órganosminerales nutricionalmente óptimos para cultivos orgánicos emergentes (cacao, café, banano y palto). Contrato 250-PNICP-ITAI-2015- Innóvate Perú.

\section{Literatura Citada}

Álvarez, E.; Viade, A.; Fernández-Marcos, M.L.; HernándezNistal, J.

2010. Limestone particle size and liming scheduling influence soil properties and pasture production. Soil Sci., 175(12): 601-613.

Barber, S.A.

1984. Liming materials and practices. En: Adams, F.,(Ed.) Soil acidity and liming. Agron. Monograph $\mathrm{N}^{\circ} 12,2 \mathrm{da}$ Ed. Am. Soc. of Agron., Crop Sci. Soc. Am., Soil Sci. Soc. Am. Madison, WI, US. pp. 171-209.

Ciesielski, H.; Sterckeman, T.; Santerne, M.; Willery, J. 1997. A comparison between three methods for the determination of cation exchange capacity and exchangeable cations in soils. Agronomie, EDP Sciences, 17(1): 9-16.

Curtin, D.; Smillie, G.W.
1995. Effects of incubation and $\mathrm{pH}$ on soil solution and exchangeable cation ratios. Soil Sci. Soc. Am. J., 59: 1006-1011.

Diario Gestión

2018. Producción avícola crecería alrededor de 4\% en el 2018 en Perú. 27 de febrero 2018. Disponible en: https://gestion.pe/economia/ produccion- avicola- creceria-alrededor-4-2018-peru-228153.

Haby, V.A.; Leonard, A.T.

2002. Limestone quality and effectiveness for neutralizing soil acidity. Comm. Soil Sci. Plant Anal., 33(15-18): 2935-2948.

Hincke, M.T.; Nys, Y.; Gautron, J.; Mann, K.; RodríguezNavarro, A.B. McKee, M.D.

2012. The eggshell: structure, composition and mineralization. Front. Biosci. 17, 1266-1280 
Holmes, J.; Kassel, P.

2006. Can ground eggshells be used as a liming source? In: Integrated Crop Management Conference.Iowa State University. October, 2006. Ia, US. pp. 235-238.

Holmes, J.D.; Rueber, D.

2013. Use of ground eggshells as a liming source. Iowa State research farm progress reports 1959. Disponible en: http:// lib.dr.iastate.edu/farms_reports/1959.

Kamprath, E.J.

1970. Exchangeable aluminum as a criterion for liming leached mineral soils. Soil Sci. Soc. Am. J., 34: 252-254.

King'ori, A.M.

2011. A Review of the Uses of Poultry Eggshells and Shell Membranes. Int. J. Poult. Sci., 10(11): 908-912.

Mehlich, A.

1984. Mehlich 3 soil test extractant: A modification of Mehlich 2 extractant. Comm. Soil Sci. Plant Anal., 15(12): 1409-1416.

Miyazawa, M.; Pavan, M.A.; Ziglio, C.O.; Franchini, J.C.

2001. Reduction of exchangeable calcium and magnesium in soil with increasing pH. Braz. Arch. Biol. Technol., 44(2): 149-153.

Nys, Y.; Gautron, J.; García-Ruiz, J.M.; Hincke, M.T.

2004. Avian eggshell mineralization: biochemical and functional characterization of matrix proteins. C.R. Palevol, 3: 549-562.

Nys, Y.; Hincke, M.T. Arias, J.L.; García-Ruiz, J.M.; Solomon, S.E.

1999. Avian eggshell mineralization. Poult. Avian Biol. Rev., 10(3): 143-166.
Ok, Y.S.; Lee, S.S.; Jeon, W-T.; Oh, S.-E.; Usman, A.R.A.; Moon, D.H.

2011. Application of eggshell waste for the immobilization of cadmium and lead in a contaminated soil. Environ. Geochem. Health, 33:31-39.

Panheleux, M.; Bain, M.; Fernández, M.S.; Morales, I.; Gautron, J.; Arias, J.L.; Solomon, S.E.; Hincke, M.; Nys, Y.

1999. Organic matrix composition and ultrastructure of eggshell: a comparative study. Br. Poult. Sci., 40: $240-252$

Parsons, A.H

1982. Structure of the eggshell. Poult. Sci. 61(10): 2013-2021.

R Core Team.

2017. R: A language and environment for statistical computing. R Foundation for Statistical Computing, Vienna, Austria. Dsiponible en: http://www.R-project.org/.

Romanoff, A.L.; Romanoff, A.J.

1949. The Avian Egg. John Wiley \& Sons, Inc., New York, NY.

Smith, D.L.; Hayward, J.L.

2010. Bacterial decomposition of avian eggshell: a taphonomic experiment. Palaios, 25: 318-326.

Yuan, T.L.

1959. Determination of exchangeable hydrogen in soils by a titration method. Soil Sci., 88(3): 164-167.

Yuen, S.H.; Pollard, A.G.

1953. Determination of nitrogen in soil and plant materials: Use of boric acid in the micro-kjeldahl method. $J$. Sci. Food Agric., 4(10): 490-496. 